\title{
Anosognosia and schizophrenia: the ethical intersection of insight, treatment and coercion James Marley
}

\author{
Address: Loyola University Chicago School of Social Work, 820 N. Michigan Avenue, Chicago, Illinois 60011, USA \\ from WPA Thematic Conference. Coercive Treatment in Psychiatry: A Comprehensive Review \\ Dresden, Germany. 6-8 June 2007 \\ Published: 19 December 2007 \\ BMC Psychiatry 2007, 7(Suppl I):S20 doi:10.1 I86/I47I-244X-7-SI-S20
}

This abstract is available from: http://www.biomedcentral.com/I47I-244X/7/SI/S20

(c) 2007 Marley; licensee BioMed Central Ltd.

\section{Background}

Anosognosia is a symptom present in some individuals diagnosed with schizophrenia. This neurological condition can greatly impair or eliminate the person's ability to have insight into the presence and/or nature of his or her illness. Such impairment in insight raises important ethical issues regarding how these individuals should be viewed with regards to autonomy, free will, self-determination and the extent to which coercion (such as involuntary hospitalization or forced medication) is justifiable. This paper will discuss this condition and explore the ethical implications and tensions brought on by anosognosia.

\section{Methods}

The presentation will be based on the author's clinical experience with this population as well as the research and literature on anosognosia, ethics of care, and coercion. In particular, the work of Stephen Darwall [1], Xavier Amador [2], and others will be used to explore the perspective of ethics of care as the basis for addressing these ethical tensions. Case examples from the presenter's clinical practice will help illustrate the nature of these ethical tensions.

\section{Results}

The presentation will include a model and rationale based on ethics of care that may be helpful in resolving the ethical tensions generated by the symptom of anosognosia. The model presents an ethical decision making process as well as clinical steps mental health practitioners can utilize to resolve such ethical tensions when issues of coercion are at stake.

\section{Conclusion}

Under some circumstances, certain levels of coercion may be justified based on an ethics of care approach when individuals with schizophrenia have substantially impaired insight into the presence and nature of their illness.

\section{References}

I. Darwall S: Welfare and Rational Care Princeton: Princeton University Press; 2002.

2. Amador X, David A, (Eds): Insight and Psychosis Oxford: Oxford University Press; 1998. 